\title{
Correction to: Efficacy of topical agents for prevention of postoperative sore throat after single lumen tracheal intubation: a Bayesian network meta-analysis Efficacité des agents topiques pour la prévention des maux de gorge postopératoires après une intubation avec tube endotrachéal simple lumière : une méta-analyse bayésienne en réseau
}

\author{
Narinder P. Singh, MD • Jeetinder K. Makkar, MD $\mathbb{D}$ - Ron B. Cappellani, FRCPC • \\ Ashish Sinha, MD • Anand Lakshminarasimhachar, MD • Preet Mohinder Singh, MD
}

Published online: 27 October 2020

(c) Canadian Anesthesiologists' Society 2020

Correction to: Can J Anesth/J Can Anesth (2020) 67:1624-1642

https://doi.org/10.1007/s12630-020-

01792-4

In the article entitled: "Efficacy of topical agents for prevention of postoperative sore throat after single lumen tracheal intubation: a Bayesian network meta-analysis" published online and in the November print issue of the Journal, Can J Anesth 2020; 67: 1624-42, "DIC" should be defined as "deviance information criterion" (instead of "disseminated intravascular coagulation").

Publisher's Note Springer Nature remains neutral with regard to jurisdictional claims in published maps and institutional affiliations.

The original article can be found online at https://doi.org/10.1007/ s12630-020-01792-4.

\footnotetext{
N. P. Singh, MD

Department of Anesthesia, Perioperative and Pain Medicine,

University of Manitoba, Winnipeg, MB, Canada

MMIMSR, MM (DU), Mullana-Ambala, India

J. K. Makkar, MD (凹)

Department of Anaesthesia and Intensive Care, Post Graduate Institute of Medical Education and Research, Sector 12,

Chandigarh 160012, India

e-mail: jeet1516@gmail.com
}

R. B. Cappellani, FRCPC

Department of Anesthesia, Perioperative and Pain Medicine,

University of Manitoba, Winnipeg, MB, Canada

A. Sinha, MD

University of California, Riverside/Riverside Community

Hospital, Riverside, CA, USA

A. Lakshminarasimhachar, MD - P. M. Singh, MD

Department of Anesthesia, Washington University in Saint Louis, Saint Louis, MO, USA 